\title{
Preparation, Characterization and Study of the Photodecolorization of Mixed-Ligand Binuclear Co(II) Complex of Schiff Base by ZnO
}

\author{
Suhad Kareem Abass ${ }^{1}$, Jassim Abbas Al-Hilfi' ${ }^{2}$, Sawsan Khudhair Abbas ${ }^{1}$, and Luma Majeed Ahmed ${ }^{1, *}$ \\ ${ }^{1}$ Department of Chemistry, College of Science, University of Kerbala, Kerbala 56001, Iraq \\ ${ }^{2}$ Department of Chemistry, Collage of Science, University of Misan, Misan 62001, Iraq
}

\section{*Corresponding author:}

email:luma.ahmed@uokerbala.edu.iq

Received: March 15, 2019

Accepted: August 15, 2019

DOI: $10.22146 /$ ijc. 44192

\begin{abstract}
In this work, a new mixed-ligand binuclear Co(II) complex of Schiff base was prepared. Moreover, the characterization of this prepared complex was performed by measurement of melting points, UV-Vis spectra, FT-IR spectra, and magnetic susceptibility measurements, and later compared with metal and ligand solutions. It has been discovered that the Schiff bases with Co(II) ion forms a binuclear complex with a stoichiometry of molar ratio 1:2 from "metal:ligand". The photodecolorization of this complex was done under UV light for ZnO's suspension solution. The results of this photodecolorization showed that the greatest efficiency was obtained with the use of $\mathrm{ZnO}$ dose of $300 \mathrm{mg} / 100 \mathrm{~mL}$ and at an initial $\mathrm{pH}$ of 7 . The decolorization activation energy for this complex is a small value of $11.289 \mathrm{~kJ} \mathrm{~mol}^{-1}$. Additionally, the thermodynamic study for this reaction is non-spontaneous, endothermic and less random.
\end{abstract}

Keywords: Schiff base; binuclear Co(II) complex; photodecolorization; ZnO; UV-A light

\section{- INTRODUCTION}

In reality, the metal complexes of Schiff bases play a crucial role in the development of coordination chemistry, which has generated an enormous number of publications, ranging from pure synthetic projects to physicochemical studies [1]. They are important chelating ligands with a variety of active applications [2-3]. These Schiff bases can be employed in catalytic, photochemical biological activities such as antiviral, anticancer and antifungal activities [4], electrochemical processes such as oxidation reactions [5] and agriculture applications [6]. As a result, they are also used as ligands to obtain metal complexes because they have high stability of the coordinating compounds and good solubility in common solvents [7]. The produced metal complexes of Schiff bases can serve as models in the understanding of biological systems [8-9]. The reaction medium affects the kinetics and mechanism of chemical transformations, which is considered one of the key problems of modern physical chemistry. In addition, the polarity of the medium as a solvent effect [10] and the temperature change [11] were extensively researched for organic compounds under photolysis. However, the photo reaction is helpful in the presence of light for the degradation of the color of organic molecules.

Direct photochemical transformation occurs closely when the energy of light attacks the bonds within an organic compound [12] that absorbs the light and leads to the treatment of effluent water. This process indicates the occurrence of chemical change and leads to the formation of carbon dioxide and treated water [13]. The purpose of this manuscript is to prepare a new mixed-ligand binuclear Co(II) complex of Schiff base and then investigate the characteristics of the components of these compounds by using UV-Vis. spectrometry, FT-IR spectrometry, magnetic measurements, and melting points. Moreover, the photodecolorization of this prepared complex is conducted under distinct circumstances such as $\mathrm{ZnO}$ dose, initial $\mathrm{pH}$ and the effect of temperature.

\section{- EXPERIMENTAL SECTION}

\section{Materials}

All the used chemicals and solvents such as ethanol, 
glacial acetic acid, DMSO, ethanol, DMF and other solvents were used in high purity. Benzedrine, salicylaldehyde, cobalt chloride hexa-hydrates $\left[\mathrm{CoCl}_{2} \cdot 6 \mathrm{H}_{2} \mathrm{O}\right]$, ethanol, DMF, DMSO, potassium hydroxide and $o$-phenylenediamine were supplied by BDH and Sigma-Aldrich companies. Commercial $\mathrm{ZnO}$ was purchased from Fluka Company in $99.5 \%$ purity.

\section{Instrumentation}

The melting point was measured by melting point apparatus (Stuart-England). FT-IR spectra were recorded in the range of $4000-400 \mathrm{~cm}^{-1}$ as $\mathrm{KBr}$ disc with a FT-IR8000 S-Shimadzu spectrophotometer (Japan). Electronic spectra with methyl formamide (DMF) as a solvent in concentration $1 \times 10^{-3} \mathrm{M}$ at room temperature and the concentrations of binuclear $\mathrm{Co}(\mathrm{II})$ complex after irradiation were recorded by using a Shimadzu UV-240 UV-visible spectrophotometer (Japan). The magnetic measurements for samples were detected using auto Magnetic susceptibility balance-MSBMKI-USA.

\section{Procedure}

\section{Synthesis of binuclear Co(II) complex}

In a round bottom flask with a capacity of $100 \mathrm{~mL}$,
$0.5 \mathrm{~g}(0.00058 \mathrm{mmol})$ of 2,2-(([1,1'-biphyneyl $]-4,4$ 'diylbis (azanylylidene)) bis (methanylylidene)) dipheno ligand $\left(\mathrm{H}_{2} \mathrm{~L}\right)$ was dissolved in potassium hydroxideethanol solution. This solution was mixed with $0.2 \mathrm{~g}$ $(0.00116 \mathrm{mmol})$ of $o$-phenylenediamine, and $25 \mathrm{~mL}$ of $\mathrm{Co}(\mathrm{II})$ ethanol-solution containing $0.0137 \mathrm{~g}(0.00116 \mathrm{~mol})$ $\left[\mathrm{CoCl}_{2} \cdot 6 \mathrm{H}_{2} \mathrm{O}\right.$ ] to produce the mole ratio of $\mathrm{H}_{2} \mathrm{~L}:$ :ophenylene diamine:metal of 1:2:2. The mixture was refluxed with heating at $55{ }^{\circ} \mathrm{C}$ for $2-3 \mathrm{~h}$. The final product (greenish brown) was filtered and washed using hot ethanol and lastly dried for $24 \mathrm{~h}$. The melting point for this complex was recorded at $296{ }^{\circ} \mathrm{C}$ with the yield $75 \%$, as shown in Scheme 1.

\section{Method of photodecolorization}

The photocatalytic decolorization reactions of the binuclear $\mathrm{Co}$ (II) complex with $\mathrm{ZnO}$ were made by using a homemade photoreactor shown in Fig. 1. This photo reactor consists of a wooden box. This wooden box contains a magnetic stirrer, a fan, a beaker for the reaction and a High pressure mercury lamp-250 Watts (Radium-Germany) as the radiation source, which has a light intensity equal to $1.458 \times 10^{-7} \mathrm{Ens} \mathrm{s}^{-1}$ by using a chemical actinometric solution [14]. In this work, an
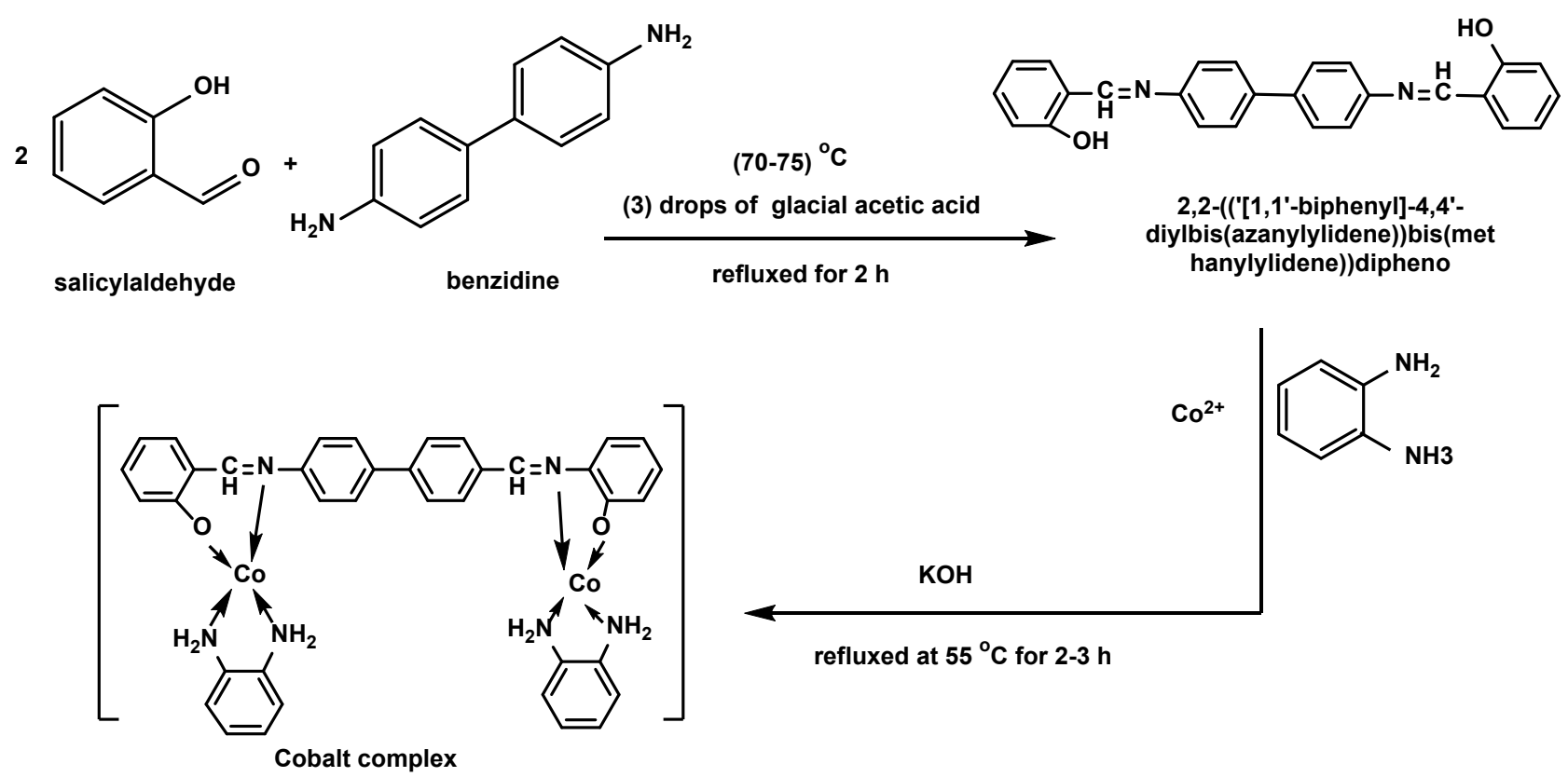

Scheme 1. Schematic diagram for the preparation of the ligand and cobalt complex 


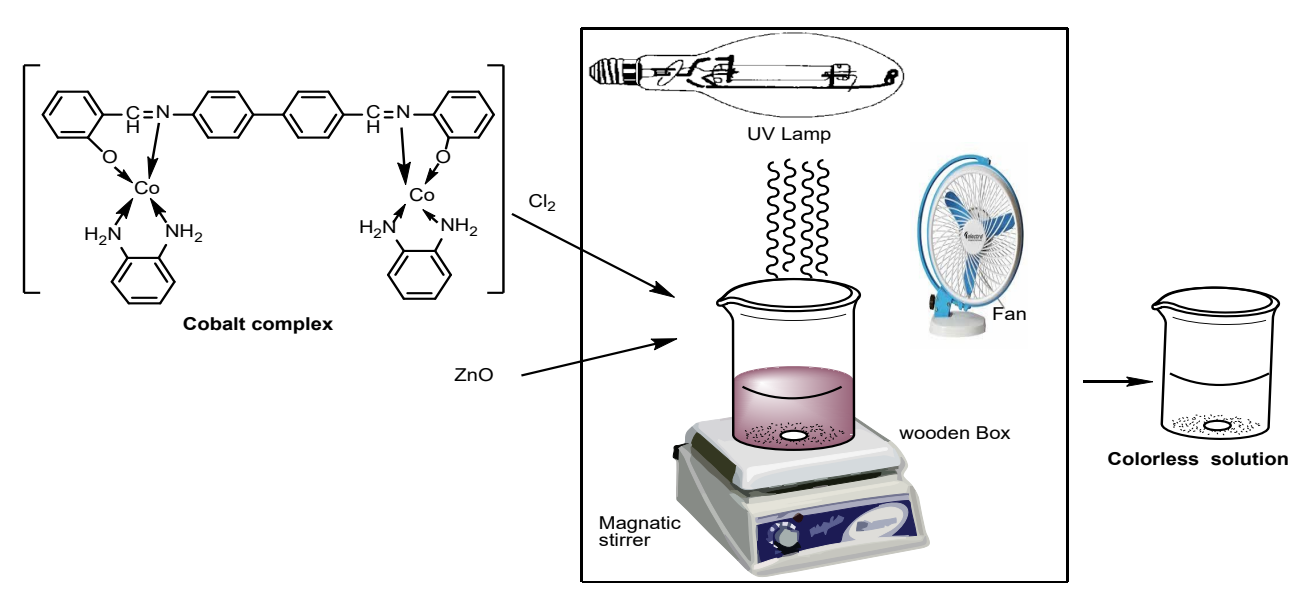

Fig 1. The photo reaction system for the decolorization of the binuclear $\mathrm{Co}$ (II) complex

appropriate amount of commercial $\mathrm{ZnO}$ was added to 50 $\mathrm{mL}$ of binuclear $\mathrm{Co}(\mathrm{II})$ complex solution with continuous mixing by a magnetic stirrer.

In the beginning, the dark reaction was carried out for $30 \mathrm{~min}$, when UV-A light illuminated the generated suspension solution. At steady time periods, approximately $3 \mathrm{~mL}$ of the formed suspension solution was taken away and centrifuged twice to guarantee the removal of all the fine $\mathrm{ZnO}$ catalyst particles at $4000 \mathrm{rpm}$ for $10 \mathrm{~min}$. The absorbance of the residue complex in the solution was recorded by using a UV-Vis spectrophotometer (Shimadzu-UV-240) at $417 \mathrm{~nm}$.

At the low concentration of the studied complex, the rate constant $\left(\mathrm{k}_{\mathrm{app}}\right)$ was explained by Eq. (1), which is based on the Langmuir-Hinshelwood kinetic expression [15].

$\ln \left(\frac{\mathrm{C}_{0}}{\mathrm{C}_{\mathrm{t}}}\right)=\mathrm{k}_{\mathrm{app}} \cdot \mathrm{t}$

where $\mathrm{C}_{0}$ is an initial concentration of binuclear $\mathrm{Co}(\mathrm{II})$ complex without light (dark reaction) or 0 min of irradiation. $\mathrm{C}_{t}$ is the concentration of the same studied complex at the time of irradiation.

The photodecolorization efficiency (PDE) of binuclear $\mathrm{Co}(\mathrm{II})$ complex from aqueous solution is expressed by Eq. (2) [16].

$\mathrm{PDE}=\left(\frac{\mathrm{C}_{0}-\mathrm{C}_{\mathrm{t}}}{\mathrm{C}_{0}}\right) \times 100$

\section{- RESULTS AND DISCUSSION}

\section{Physical Properties}

Some physical features for $\mathrm{H}_{2} \mathrm{~L}$ and its complex are explained in Table 1, including the change in the color and the melting points. The color of the ligand is altered from bright yellow to greenish brown when it is reacting with cobalt ion. In addition, the elevated melting point of the complex compared with the melting point of the ligand indicates the high stability of the complex towards air and light.

\section{FT-IR Spectra}

The IR absorption spectrum of the Schiff base for the $\mathrm{H}_{2} \mathrm{~L}$ in Fig. 2 shows the absence of two absorption bands at 3412 and $3295 \mathrm{~cm}^{-1}$ which belongs to $-\mathrm{NH}_{2}$ stretching of benzidine, and $\mathrm{C}=\mathrm{O}$ absorption band at $1700 \mathrm{~cm}^{-1}$ of salicylaldehyde, and the appearance of $\mathrm{C}=\mathrm{N}$ absorption band at $1618 \mathrm{~cm}^{-1}$. The infrared spectrum of the $\mathrm{H}_{2} \mathrm{~L}$ ligand appeared as a broad band at $\left(3465 \mathrm{~cm}^{-1}\right)$, which indicated the $-\mathrm{OH}$ group [17]. The $v(\mathrm{O}-\mathrm{H})$ band is absent in the IR spectrum of the Co-complex confirmed by the absence of the $\mathrm{O}-\mathrm{H}$ bending band for $\mathrm{H}_{2} \mathrm{~L}$ in the complex of the mixed ligand. Meanwhile, the appearance of the band in the range of $3330-3340 \mathrm{~cm}^{-1}$ indicated the presence of the $-\mathrm{NH}_{2}$ group. The absorption band of the $\mathrm{C}=\mathrm{N}$ group in $\mathrm{H}_{2} \mathrm{~L}$ appeared at $1618 \mathrm{~cm}^{-1}[18]$. The band of the $\mathrm{C}=\mathrm{N}$ group was shifted to

Table 1. Physical properties for the ligand $\mathrm{H}_{2} \mathrm{~L}$ and the binuclear Co(II) complex

\begin{tabular}{llcl}
\hline Compounds & \multicolumn{1}{c}{ Color } & $\begin{array}{c}\text { Melting } \\
\text { points }\left({ }^{\circ} \mathrm{C}\right)\end{array}$ & Yield \\
\hline $\mathrm{H}_{2} \mathrm{~L}$ & Bright Yellow & 209 & $90.01 \%$ \\
$\left.\left[\mathrm{Co}_{2}(\mathrm{OPD})_{2} \mathrm{~L}\right)\right] \mathrm{Cl}_{2}$ & Greenish Brown & 296 & $75 \%$ \\
\hline
\end{tabular}




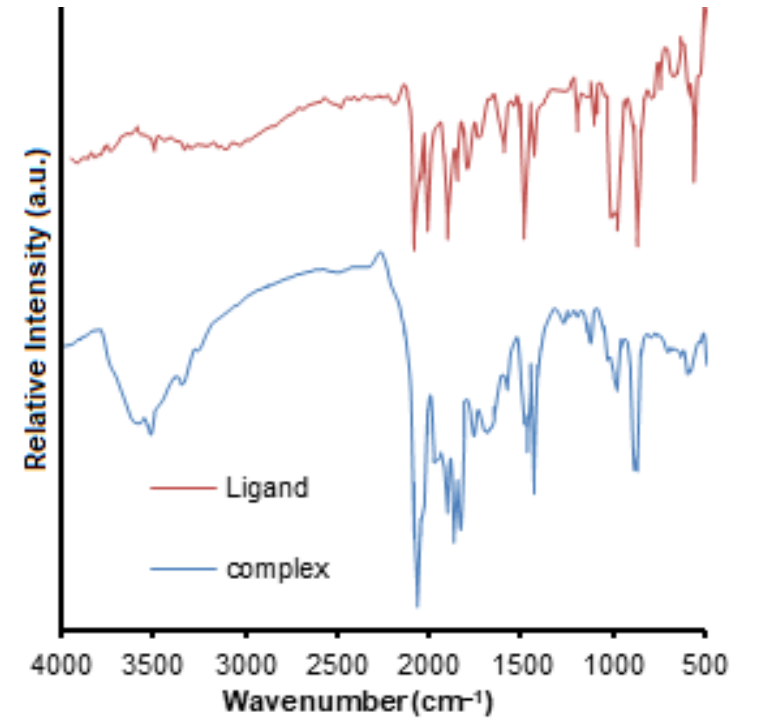

Fig 2. FT-IR spectra of $\mathrm{H}_{2} \mathrm{~L}$ and $\left[\mathrm{Co}_{2}(\mathrm{OPD})_{2}(\mathrm{~L})\right] \mathrm{Cl}_{2}$ complex

lower frequencies because of the coordination with metal ions through the nitrogen atom shown in Fig. 2. The new bands that appeared in the regions, $468.72-542.02 \mathrm{~cm}^{-1}$, may be due to the generation of $\mathrm{M}-\mathrm{O}$, and $\mathrm{M}-\mathrm{N}$ bands [19].

\section{UV-Vis Spectra}

Two absorption peaks were displayed in the UV-Vis spectrum of the ligand $\mathrm{H}_{2} \mathrm{~L}$ as shown in Fig. 3. The first peak at $279 \mathrm{~nm}\left(35842 \mathrm{~cm}^{-1}\right)$ was assigned to $\pi-\pi^{*}$ electronic transition of the benzene rings. The second peak at $370 \mathrm{~nm}\left(27027 \mathrm{~cm}^{-1}\right)$ was attributed to $n-\pi^{*}$ electronic transition of the non-bonding electrons (i.e. free electron pair) that is found on the nitrogen in the Schiff base part of the ligand as the transition of the molecular orbital of $\mathrm{C}=\mathrm{N}$ chromophore [20-21]. Meanwhile the UV-Vis spectrum of the binuclear $\mathrm{Co}$ (II) complex shown in Fig. 3 displayed three absorption peaks. The first peak at $272 \mathrm{~nm}$ $\left(36764 \mathrm{~cm}^{-1}\right)$ was assigned to the ligand field, while the second peak at $363 \mathrm{~nm}\left(27548 \mathrm{~cm}^{-1}\right)$ refers to the charge transfer electronic transition. The third peak was attributed to d-d electronic transition tetrahedral geometry around the central ion $\mathrm{Co}$ (II) at $979 \mathrm{~nm}\left(10214 \mathrm{~cm}^{-1}\right)$, which mostly observes as a new weak and much broader peak [20].

\section{Magnetic Susceptibility Measurements of Complexes}

The magnetic moment of this complex was 5.089 B.M.
This indicates that the generated complexes has tetrahedral form [20], as observed in Table 2.

\section{Photodecolorization Reaction of $\left[\mathrm{Co}_{2}(\mathrm{OPD})_{2}(\mathrm{~L}) \mathrm{Cl}_{2}\right.$ Complex}

\section{Effect of ZnO dose on the decolorization of $\left[\mathrm{CO}_{2}(\mathrm{OPD})_{2}(\mathrm{~L})\right] C \mathrm{Cl}_{2}$ complex}

The effect of $\mathrm{ZnO}$ doses in the range of $0.1-0.5$ $\mathrm{g} / 100 \mathrm{~mL}$ is depicted in Fig. 4 and 5 . This study is essential to eschew the excess of the catalyst used, which reduces the efficiency of the photoreaction. The apparent rate constants for the decolorization of binuclear $\mathrm{Co}(\mathrm{II})$ complex were raised with increased dose of $\mathrm{ZnO}$ with a maximum value of $0.3 \mathrm{~g} / 100 \mathrm{~mL}$, due to the sufficient amount of active sites on the catalyst surface to raise the chance of radical formation [22-23]. On the other hand, the high amount of $\mathrm{ZnO}$ induced the decrease of the rate of this reaction due to the reduction of the penetration ability of light into this solution which acts as a screen [24-25]. In Fig. 5, the maximum PDE\% was reached at $99.129 \%$ after $70 \mathrm{~min}$.

\section{Effect of the initial $\mathrm{pH}$ on the decolorization of $\left[\mathrm{CO}_{2}(\mathrm{OPD})_{2}(\mathrm{~L})\right] \mathrm{Cl}_{2}$ complex}

The study of the initial $\mathrm{pH}$ of the aqueous solution

Table 2. Magnetic susceptibility measurements of binuclear $\mathrm{Co}(\mathrm{II})$ complex

\begin{tabular}{lcccc}
\hline Complex & $\begin{array}{c}\mathrm{Xg} \\
\times 10^{-6}\end{array}$ & $\begin{array}{c}\mathrm{XM} \\
\times 10^{-6}\end{array}$ & $\begin{array}{c}\mathrm{XA} \\
\times 10^{-6}\end{array}$ & $\begin{array}{c}\mu \text { eff } \\
\text { B.M }\end{array}$ \\
\hline$\left[\mathrm{Co}_{2}(\mathrm{OPD})_{2}(\mathrm{~L})\right] \mathrm{Cl}_{2}$ & 13.5 & 10731.15 & 11128.15 & 5.089 \\
\hline
\end{tabular}

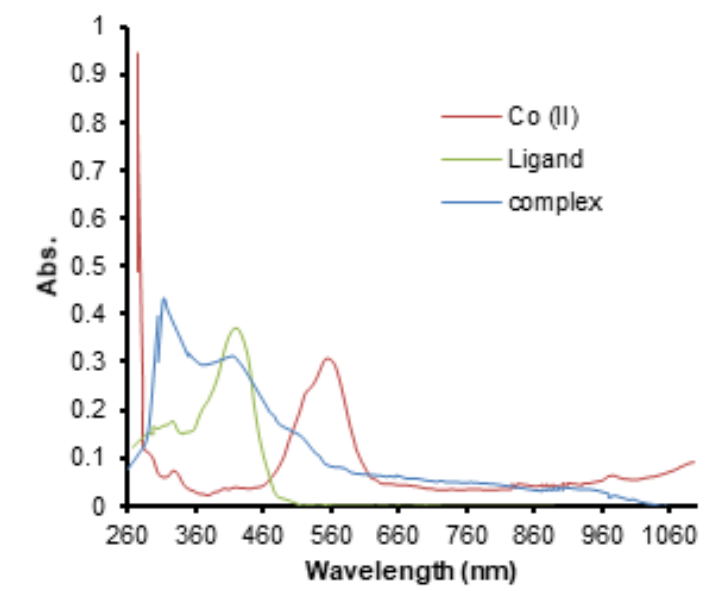

Fig 3. UV-Vis spectra for $\mathrm{H}_{2} \mathrm{~L}$ ligand, Metal (Co(II) and complex $\left[\mathrm{Co}_{2}(\mathrm{OPD})_{2}(\mathrm{~L})\right] \mathrm{Cl}_{2}$ 


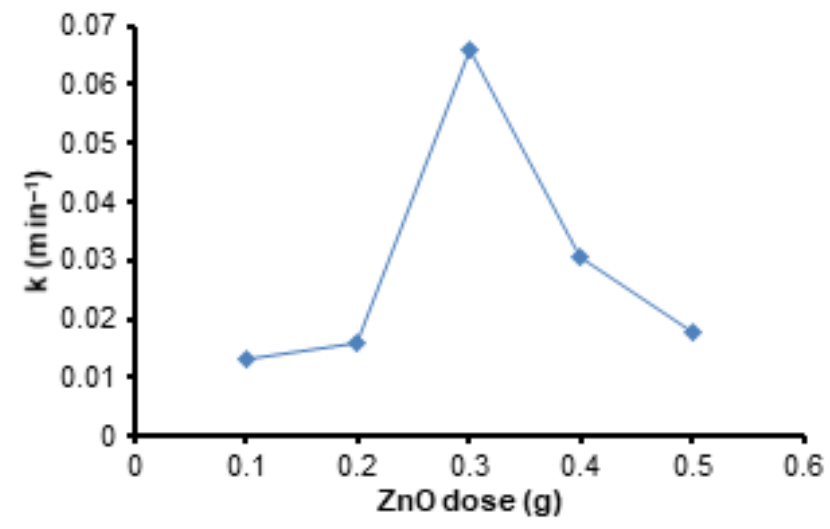

Fig 4. Effect of $\mathrm{ZnO}$ dosage on the apparent rate constant of reaction. At conditions: $\mathrm{ZnO}$ dosage $0.1-0.5 \mathrm{~g} / 100 \mathrm{~mL}$, binuclear Co(II) complex conc. 25 ppm, initial pH of solution 7.00 and $\mathrm{T} 311.15 \mathrm{~K}$

for this complex was monitored at a $\mathrm{pH}$ range of 3-11, as explained in Fig. 6 and 7. The pH is considered to be a vital factor in increasing the decolorization of this complex because it affects the nature of the complex, and also the nature and surface properties of $\mathrm{ZnO}$, thus affecting the hydroxyl radical generated [26-27]. The maximum decolorization for the binuclear Co(II) complex occurred at $\mathrm{pH} 7$ with maximum $\mathrm{PDE} \%$ equal to $99.128 \%$ at $70 \mathrm{~min}$. In fact, the results demonstrated that when the $\mathrm{pH}$ was more or less than $\mathrm{pH} 7$, the rate of decolorization and the PDE\% declined, based on the following two causes [27]: At elevated acidic medium,

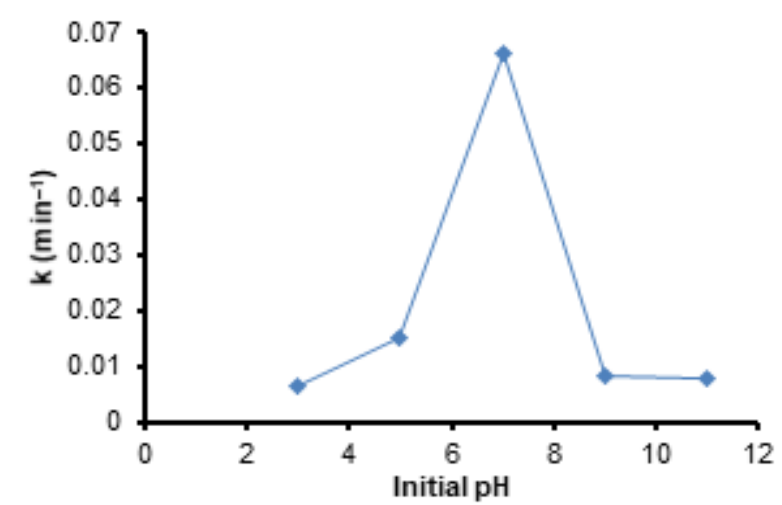

Fig 6. Effect of initial $\mathrm{pH}$ of binuclear $\mathrm{Co}(\mathrm{II})$ complex solution on the apparent rate constant of reaction. Conditions: $\mathrm{ZnO}$ dose $0.3 \mathrm{~g} / 100 \mathrm{~mL}$, binuclear Co(II) complex conc. $25 \mathrm{ppm}$, initial pH of solution 3-11 and T $311.15 \mathrm{~K}$

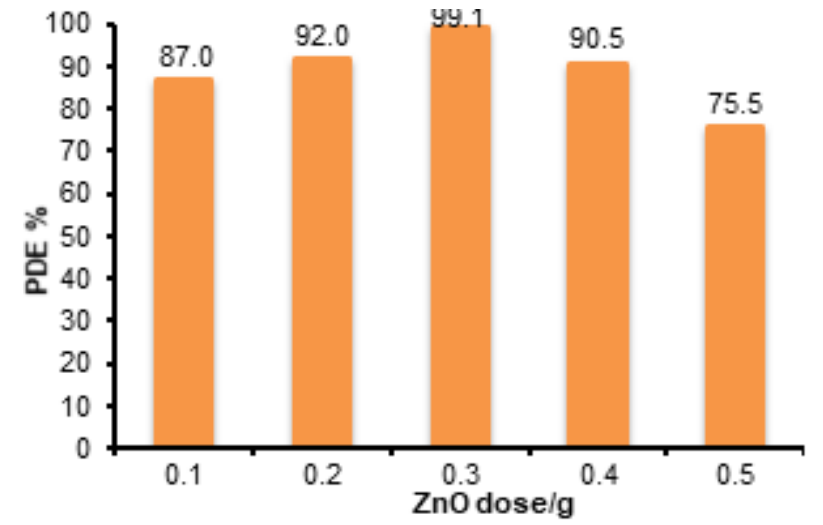

Fig 5. PDE \% of binuclear $\mathrm{Co}$ (II) complex solution at different $\mathrm{ZnO}$ dosage. At conditions: $\mathrm{ZnO}$ dosage $0.1-$ $0.5 \mathrm{~g} / 100 \mathrm{~mL}$, binuclear Co(II) complex conc. $25 \mathrm{ppm}$, initial pH of solution 7.00 and $\mathrm{T} 311.15 \mathrm{~K}$

$\mathrm{ZnO}$ may have undergone photocorrosion and altered to $\mathrm{Zn}(\mathrm{II})$ ion $[23,28]$.

$\mathrm{ZnO}+2 \mathrm{~h}^{+} \rightarrow \mathrm{Zn}^{2+}+\frac{1}{2} \mathrm{O}_{2} \quad$ (acidic $\left.\mathrm{pH}\right)$

or

$\mathrm{ZnO}+2 \mathrm{H}^{+} \rightarrow \mathrm{Zn}^{2+}+\mathrm{H}_{2} \mathrm{O} \quad$ (acidic $\left.\mathrm{pH}\right)$

Inversely, in high basic $\mathrm{pH}, \mathrm{ZnO}$ can be negatively charged and lead to the decrease in the photocatalytic activity $[23,25]$.

$\mathrm{Zn}-\mathrm{OH}+\mathrm{OH}^{-} \rightarrow \mathrm{Zn}-\mathrm{O}^{-}+\mathrm{H}_{2} \mathrm{O} \quad$ (basic $\mathrm{pH}$ )

or

$\mathrm{ZnO}+\mathrm{H}_{2} \mathrm{O}+2 \mathrm{OH}^{-} \rightarrow\left[\mathrm{Zn}(\mathrm{OH})_{4}\right]^{2-} \quad($ basic $\mathrm{pH})$

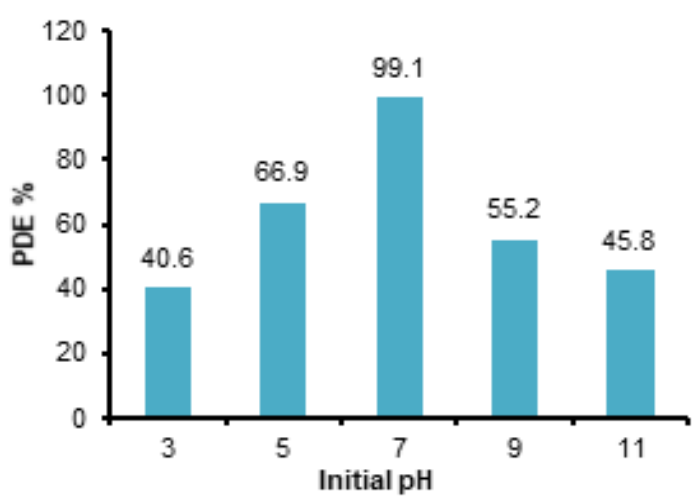

Fig 7. PDE \% of binuclear $\mathrm{Co}$ (II) complex solution at different $\mathrm{ZnO}$ dosage. Conditions: $\mathrm{ZnO}$ dose $0.3 \mathrm{~g} / 100 \mathrm{~mL}$, binuclear Co(II) complex conc. $25 \mathrm{ppm}$, initial $\mathrm{pH}$ of solution $3-11$ and $\mathrm{T} 311.15 \mathrm{~K}$. 


\section{Effect of temperature on the decolorization of $\left[\mathrm{CO}_{2}(\mathrm{OPD})_{2}(\mathrm{~L})\right] \mathrm{Cl} \mathrm{l}_{2}$ complex}

At temperatures in the range of $288.15-303.15 \mathrm{~K}$, the results in Fig. 8 and 9 show that the decolorization process for the binuclear $\mathrm{Co}$ (II) complex is elevated with raised temperature. The plotted Arrhenius equation (Eq. (7)) $[29,23]$, and Eyring-Polanyi equation (Eq. (8)) [25,30] were demonstrated.

$\ln \mathrm{k}_{\mathrm{app}}=\frac{-\mathrm{E}_{\mathrm{a}}}{\mathrm{RT}}+\ln \mathrm{A}$

where $E_{a}$ is activation energy, $k$ is rate constant, $R$ is gas constant, $\mathrm{T}$ is the temperature of reaction and $\mathrm{A}$ is a frequency constant.

$\Delta \mathrm{H}^{\#}$ and $\Delta \mathrm{S}^{\#}$ were calculated based on the EyringPolanyi equation [25,30-31]

$\ln \left(\frac{\mathrm{k}_{\mathrm{app} .}}{\mathrm{T}}\right)=\frac{-\Delta \mathrm{H}^{\#}}{\mathrm{RT}}+\left(\ln \left(\frac{\mathrm{k}_{\mathrm{B}}}{\mathrm{h}}\right)+\frac{\Delta \mathrm{S}^{\#}}{\mathrm{R}}\right)$

where $\mathrm{k}_{\mathrm{B}}$ is a Boltzmann's constant, $\mathrm{h}$ is a Plank's constant, $\mathrm{R}$ is a gas constant and $\mathrm{T}$ is the temperature of the reaction.

The activation energy for the decolorization of the binuclear $\mathrm{Co}(\mathrm{II})$ complex is small and equals to $11.289 \mathrm{~kJ} / \mathrm{mol}$, which proves this photoreaction is fast speed [32-33] and the reaction is endothermic where the change in enthalpy equals to $8.832 \mathrm{~kJ} / \mathrm{mol}$ as listed in Table 2. $\Delta \mathrm{G}^{*}$ of the photo reaction was calculated using the Gibbs equation (Eq. (9)) based on the fitting results of the Eyring-Polanyi equation [29-31].

$\Delta \mathrm{G}^{\#}=\Delta \mathrm{H}^{\#}-\mathrm{T} \Delta \mathrm{S}^{\#}$

All fitted factors of the thermodynamics functions and the activation energy are listed in Table 3.

The positive $\Delta \mathrm{H}^{\#}$ (endothermic) and positive $\Delta \mathrm{G}^{\#}{ }_{303.15}$ (non-spontaneous) for the decolorization of the binuclear Co(II) complex demonstrated that the transition state between the complex molecules and intermediates (hydroxyl radicals) is a well solvated structure. The negative values of $\Delta S^{\#}$ for the decolorization of the binuclear $\mathrm{Co}(\mathrm{II})$ complex species formed is less random than the reactants. These results have similar behavior with other photo reactions observed by several researchers $[25,31,34]$.

\section{Mechanism of the Photodecolorization of $\left[\mathrm{CO}_{2}(\mathrm{OPD})_{2}(\mathrm{~L})\right] \mathrm{Cl}_{2}$ Complex}

The series of redox processes can take place via the presence of $\mathrm{ZnO}$ as a suspension in an aqueous solution of $\left[\mathrm{Co}_{2}(\mathrm{OPD})_{2}(\mathrm{~L})\right] \mathrm{Cl}_{2}$ complex. The best species $[16,35]$ which can decolorize the $\left[\mathrm{Co}_{2}(\mathrm{OPD})_{2}(\mathrm{~L})\right] \mathrm{Cl}_{2}$ complex are $\mathrm{HO}$ and $\mathrm{HOO}$ under irradiation by UV-A light, as explained in Fig. 10.

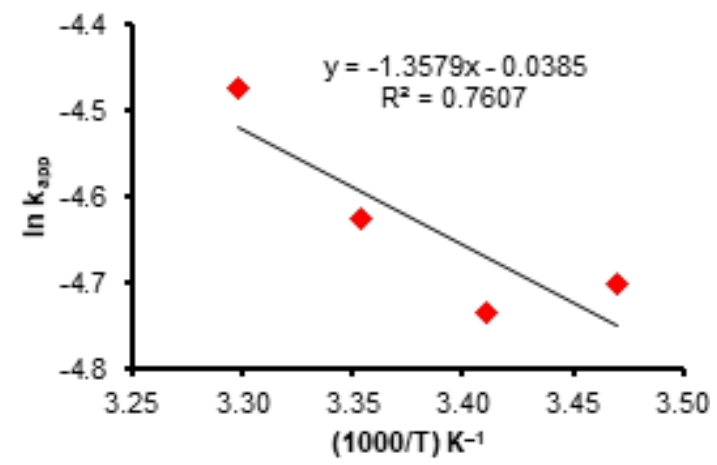

Fig 8. Arrhenius equation plotted at varying temperatures, at $288.15-303.15 \mathrm{~K}$. Conditions: $\mathrm{ZnO}$ dose $0.3 \mathrm{~g} / 100 \mathrm{~mL}$, binuclear Co(II) complex conc. $25 \mathrm{ppm}$, initial $\mathrm{pH}$ of solution 7

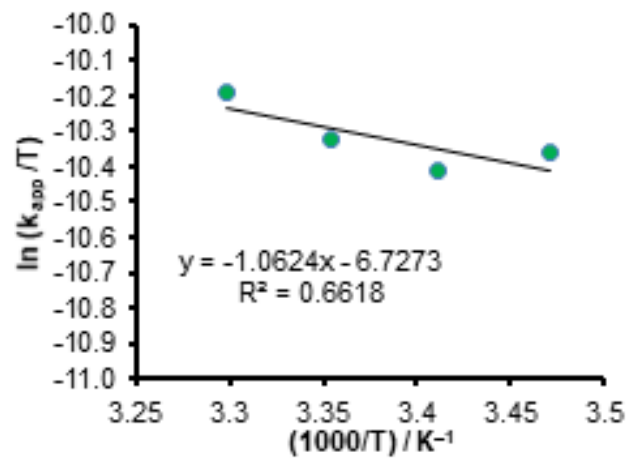

Fig 9. Eyring plot of $(\ln (\mathrm{k} / \mathrm{T}))$ vs. 1/T. Conditions: $\mathrm{ZnO}$ dose $0.3 \mathrm{~g} / 100 \mathrm{~mL}$, binuclear $\mathrm{Co}(\mathrm{II})$ complex conc. $25 \mathrm{ppm}$, initial $\mathrm{pH}$ of solution 7

Table 3. The activation energy and thermodynamic parameters of the decolorization of the binuclear $\mathrm{Co}(\mathrm{II})$ complex under UV-A light

\begin{tabular}{|c|c|c|c|c|}
\hline $\begin{array}{c}\text { Type of lamp } \\
\text { (UV-A) }\end{array}$ & $\begin{array}{c}\mathrm{E}_{\mathrm{a}} \\
\mathrm{kJ} \mathrm{mol}^{-1}\end{array}$ & $\begin{array}{c}\Delta \mathrm{H}^{\#} \\
\mathrm{~kJ} \mathrm{~mol}^{-1}\end{array}$ & $\begin{array}{c}\Delta S^{\#} \\
\mathrm{~J} \mathrm{~mol}^{-1} \mathrm{~K}^{-1}\end{array}$ & $\begin{array}{l}\Delta \mathrm{G}^{\#} 303.15 \\
\mathrm{~kJ} \mathrm{~mol}{ }^{-1}\end{array}$ \\
\hline 50 Watt & 11.289 & 8.832 & -3.666 & 9.945 \\
\hline
\end{tabular}




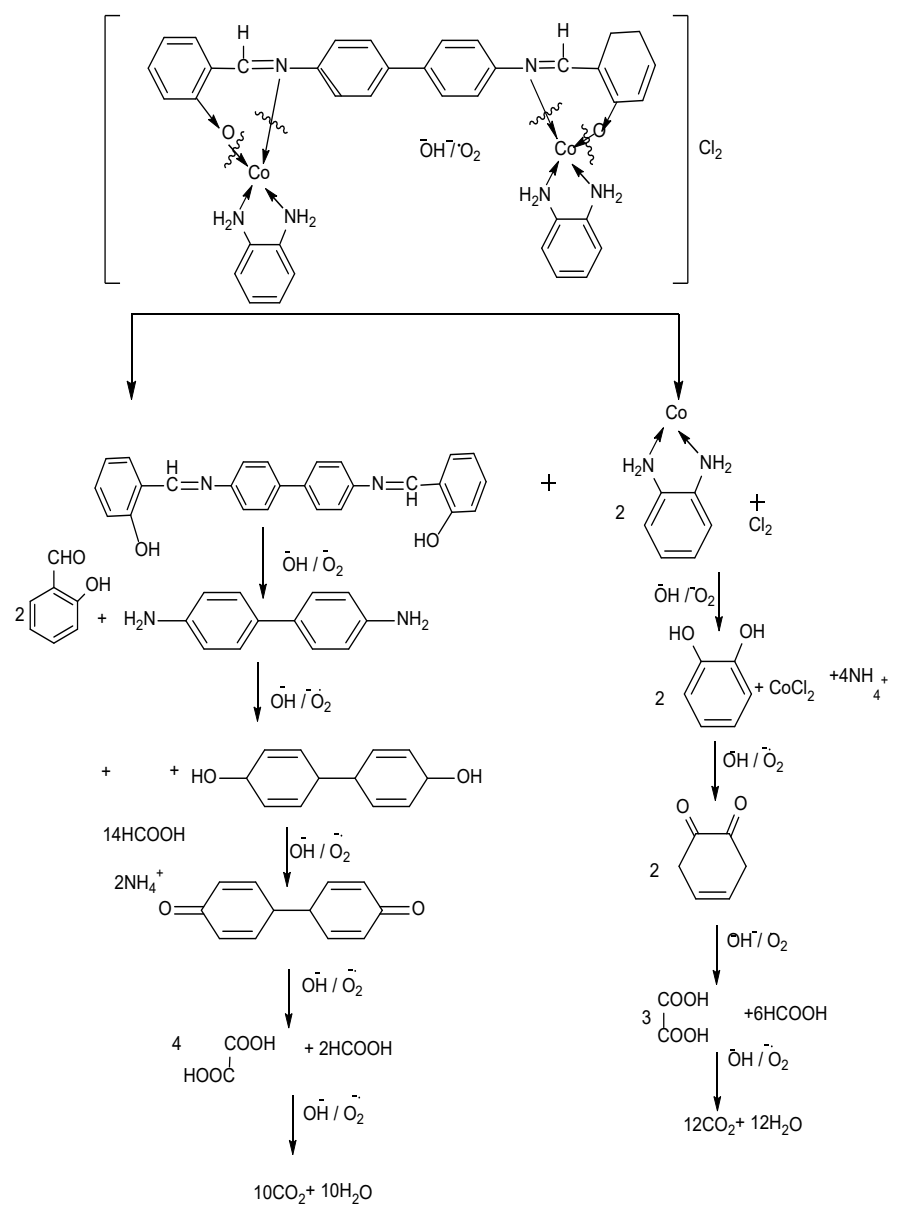

Fig10. Schematic diagram of the suggested mechanism of the photodecolorization of $\left.\left[\mathrm{Co}_{2}(\mathrm{OPD})_{2} \mathrm{~L}\right)\right] \mathrm{Cl}_{2}$ complex with photocatalyst $\mathrm{ZnO}$

\section{- CONCLUSION}

The main conclusions are referred to the forming of $\left.\left[\mathrm{Co}_{2}(\mathrm{OPD})_{2} \mathrm{~L}\right)\right] \mathrm{Cl}_{2}$ complex in the mole ratio of $1: 2$ "metal:ligand" stoichiometry and with greenish brown color. From FTIR analysis, new bands appeared in the regions, $469-542 \mathrm{~cm}^{-1}$ which may be due to the formation of $\mathrm{M}-\mathrm{O}$ and $\mathrm{M}-\mathrm{N}$ bands. The increased melting point is proven to be a binuclear Co(II) complex. In the UVVisible spectrum, the appearance of the new weak and much broader peak at $979 \mathrm{~nm}$ were attributed to d-d electronic transition tetrahedral geometry around the Co(II) central ion. The optimum conditions for photodecolorization of the binuclear $\mathrm{Co}$ (II) complex were observed at $300 \mathrm{mg}$ of $\mathrm{ZnO} / 100 \mathrm{~mL}$ from binuclear $\mathrm{Co}$ (II) complex solution, initial $\mathrm{pH}$ of 7 , with low activation energy, endothermic, less random and non-spontaneous reaction.

\section{- ACKNOWLEDGMENTS}

Authors would like to acknowledge to those who have encouraged this research at the Physical and Inorganic Laboratories at the University of Kerbala, College of Science in the Department of Chemistry in Iraq.

\section{- REFERENCES}

[1] AL-Hilfi, J.A., Abood, N., Fahad, T.A., and Turner, S., 2015, Synthesis and structural study of some new metal complexes of Schiff base from 2thenoyltrifluoroacetone with alkyl amine and its thione derivative by NMR, IR and TGA analysis methods, Der Chemica Sinica, 6 (11), 37-41.

[2] Al-Shemari, R.K., and Shafiq, Z.A., A.S., 2015, Synthesis, characterization and biological activity for binuclear complexes $\mathrm{Co}(\mathrm{II}), \mathrm{Cu}(\mathrm{II}), \mathrm{Ni}(\mathrm{II})$, $\mathrm{Mn}$ (II) and $\mathrm{Hg}$ (II) with Schiff base ligand type $\mathrm{N}_{2} \mathrm{O}_{2}$, Asian J. Pharm. Sci. Technol., 5 (3), 172-178.

[3] Samir, A.H, Hasan, H.A., Aziz, M.R., and Shaker, S.M., 2010, Synthesis of some metal complexes of azo type ligand and evaluation of their antibacterial activity, J. Coll. Educ., 1, 305-318.

[4] Hamak, K.F., and Eissa, H.H., 2013, Synthesis, characterization, biological evaluation and anti corrosion activity of some heterocyclic compounds oxazepine derivatives from Schiff bases, Org. Chem. Curr. Res., 2 (3), 121.

[5] Yang, Z., and Sun, P., 2006, Compare of three ways of synthesis of simple Schiff base, Molbank, 6, M514.

[6] Li, L., Li, Z., Wang, K., Zhao, S., Feng, J., Li, J., Yang, P., Liu, Y., Wang, L., Li, Y., Shang, H., and Wang, Q., 2014, Design, synthesis, and biological activities of aromatic gossypol Schiff base derivatives, J. Agric. Food Chem., 62 (46), 11080-11088.

[7] Gupta, Y.K., Agarwal, S.C., Madnawat, S.P., and Ram, N., 2012, Synthesis, characterization, and antimicrobial studies of some transition metal complexes of Schiff bases, Res. J. Chem. Sci., 2 (4), 68-71. 
[8] Tajmir-Riahi, H.A., 1991, Coordination chemistry of vitamin C. Part II. Interaction of L-ascorbic acid with $\mathrm{Zn}(\mathrm{II}), \mathrm{Cd}(\mathrm{II}), \mathrm{Hg}(\mathrm{II})$ and $\mathrm{Mn}(\mathrm{II})$ ions in the solid state and in aqueous solution, J. Inorg. Biochem., 42 (1), 47-55.

[9] Saravanakumar, D., Sengottuvelan, N., Priyadarshni, G., Kandaswamy, M., and Okawa, H., 2004, Synthesis of unsymmetrical 'end-off phenoxo and oximinato di bridged copper(II) and nickel(II) complexes: Spectral, electrochemical and magnetic properties, Polyhedron, 23 (4), 665-672.

[10] Kumar, R., and Yusuf, M., 2009, Photolysis of some 2-butenyl/butynylbischromones: Effect of solvent polarity, Org. Commun., 2 (1), 17-19.

[11] Shareef, K.M., Naman, S.A.M.A., and Muhamad, S.G., 2010, Temperature and $\mathrm{pH}$ affecting the catalytic photodegradation of 2,4-D and MCPA pesticides in aqueous medium, J. Koya Univ., 15, 152-159.

[12] Al-Momani, F., 2003, Combination of photooxidation processes with biological treatment, Dissertation, University of Barcelona, Spain.

[13] Gernjak, W., 2006, Solar photo-Fenton treatment of EU priority substances - Process parameters and control strategies, Dissertation, Universität für Bodenkultur Wien, Vienna.

[14] Mahammed, B.A., and Ahmed, L.M., 2017, Enhanced photocatalytic properties of pure and Cr-modified $\mathrm{ZnS}$ powders synthesized by precipitation method, $J$. Geosci. Environ. Prot., 5 (10), 101-111.

[15] Eesa, M.T., Juda, A.M., and Ahmed, L.M., 2016, Kinetic and thermodynamic study of the photocatalytic decolourization of Light Green SF Yellowish (acid green 5) dye using commercial bulk titania and commercial nanotitania, Int. J. Sci. Res., 5 (11), 1495-1500.

[16] Ahmed, L.M., Saaed, S.I., and Marhoon, A.A., 2018, Effect of oxidation agents on photo-decolorization of vitamin $\mathrm{B} 12$ in the presence of $\mathrm{ZnO} / \mathrm{UV}-\mathrm{A}$ system, Indones. J. Chem., 18 (2), 272-278.

[17] Cozzi, P.G., 2004, Metal-salen Schiff base complexes in catalysis, Chem. Soc. Rev., 33 (7), 410-421.
[18] Krishnankutty, K., Ummathur, M.B., and Sayudevi, P., 2008, Metal complexes of Schiff bases derived from dicinnamoylmethane and aromatic amines, $J$. Argent. Chem. Soc., 96 (1-2), 13-21.

[19] Singh, M.S., and Singh, P.K., 2000, A new class of organosilicon(IV) compound based upon tetradentate $\left(\mathrm{N}_{2} \mathrm{O}_{2}\right)$ chelating ligand, Main Group Met. Chem., 23 (3), 183-188.

[20] Gerloch, M., and Constable, E.G., 1994, Transition metal chemistry: The valence shell in the d-block chemistry, Wiley-VCH, Weinheim, Germany, 46-58.

[21] Aranha, P.E., dos Santos, M.P., Romera, S., and Dockal, E.R., 2007, Synthesis, characterization, and spectroscopic studies of tetradentate Schiff base chromium(III) complexes, Polyhedron, 26 (7), 1373-1382.

[22] Byrappa, K., Subramani, A.K., Ananda, S., Rai, K.M.L., Dinesh, R., and Yoshimura, M., 2006, Photocatalytic degradation of rhodamine $\mathrm{B}$ dye using hydrothermally synthesized $\mathrm{ZnO}$, Bull. Mater. Sci., 29 (5), 433-438.

[23] Fathal, E.S., and Ahmed, L.M., 2015, Optimization of photocatalytic decolourization of methyl green dye using commercial zinc oxide as a catalyst, $J$. Kerbala Univ., 13 (1), 53-63.

[24] Munesh, Swati, and Meena, R.C., 2012, Photocatalytic decolorization of Acid Red 186 using alternative developed photocatalyst MBIR Dowex 11, Res. J. Chem. Sci., 2 (9), 56-62.

[25] Ahmed, L.M., Tawfeeq, F.T., Al-Ameer, M.H.A., Al-Hussein, K.A., and Athaab, A.R., 2016, Photodegradation of Reactive Yellow 14 dye (a textile dye) employing $\mathrm{ZnO}$ as photocatalyst, J. Geosci. Environ. Prot., 4, 34-44.

[26] Ahmed, L.M., Jassim, M.A., Mohammed, M.Q., and Hamza, D.T., 2018, Advanced oxidation processes for carmoisine (E122) dye in UVA/ZnO system: Influencing $\mathrm{pH}$, temperature and oxidant agents on dye solution, JGPT, 10 (7), 248-254.

[27] Mohabansi, N.P., Patil, V.B., and Yenkie, N., 2011, A comparative study on photo degradation of methylene blue dye effluent by advanced oxidation 
process by using $\mathrm{TiO} 2 / \mathrm{ZnO}$ photo catalyst, Rasayan J. Chem., 4 (4), 814-819.

[28] Nadi, H., Alizadeh, M., Ahmadabadi, M., Yari, A.R., and Hashemi, S., 2012, Removal of reactive dyes (green, orange, and yellow) from aqueous solutions by peanut shell powder as a natural adsorbent, Arch. Hyg. Sci., 1 (2), 41-47.

[29] Hussein, Z.A., Abbas, S.K., and Ahmed, L.M., 2018, UV-A activated $\mathrm{ZrO}_{2}$ via photodecolorization of methyl green dye, IOP Conf. Ser.: Mater. Sci. Eng., 454, 012132.

[30] Ahmed, L.M., 2018, Photo-decolourization kinetics of acid red 87 dye in $\mathrm{ZnO}$ suspension under different types of UV-A light, Asian J. Chem., 30 (9), 2134-2140.

[31] Fakhri, F.H., and Ahmed, L.M., 2019, Incorporation $\mathrm{CdS}$ with $\mathrm{ZnS}$ as nanocomposite and using in photodecolorization of Congo red dye, Indones. J. Chem., 19 (4), 936-943.
[32] Qadri, M., Nisar, S., and Fatima, N., 2015, Photokinetics of the oxidation of Coomassie brilliant blue by potassium dichromate in acidic medium, Int. J. Adv. Res., 3 (2), 888-898.

[33] Kzar, K.O., Mohammed, Z.F., Saeed, S.I., Ahmed, L.M., Kareem, D.I., Hadyi, H., and Kadhim, A.J., 2019, Heterogeneous photo-decolourization of cobaltous phthalocyaninate dye (Reactive green dye) catalyzed by ZnO, AIP Conf. Proc., 2144, 020004.

[34] Gajbhiye, S.B., 2012, Photocatalytic degradation study of methylene blue solutions and its application to dye industry effluent, Int. J. Mod. Eng. Res., 2 (3), 1204-1208.

[35] Jasim, K.M., and Ahmed, L.M., 2019, $\mathrm{TiO}_{2}$ nanoparticles sensitized by safranine $\mathrm{O}$ dye using UV-A light system, IOP Conf. Ser.: Mater. Sci. Eng., $571,012064$. 